\title{
Short-term effects of simulated microgravity on morphology and gene expression in human breast cancer cells
}

\author{
F Strube, M Infanger, C Dietz, A Romswinkel, A Kraus \\ Department of Plastic, Aesthetic and Hand Surgery, Otto-von-Guericke-University, Magdeburg, Germany
}

Received: March 6, 2019

Accepted: September 18, 2019

\begin{abstract}
Introduction: Microgravity has been shown to impose various effects on breast cancer cells. We exposed human breast cancer cells to simulated microgravity and studied morphology and alterations in gene expression. Materials and methods: Human breast cancer cells were exposed to simulated microgravity in a random positioning machine (RPM) for $24 \mathrm{~h}$. Morphology was observed under light microscopy, and gene alteration was studied by qPCR. Results: After $24 \mathrm{~h}$, formation of three-dimensional structures (spheroids) occurred. BRCA1 expression was significantly increased $(1.9 \times, p<0.05)$ in the adherent cells under simulated microgravity compared to the control. Expression of KRAS was significantly decreased $(0.6 \times, p<0.05)$ in the adherent cells compared to the control. VCAM1 was significantly upregulated $(6.6 \times, 2.0 \times, p<0.05$ each $)$ in the adherent cells under simulated microgravity and in the spheroids. VIM expression was significantly downregulated $(0.45 \times, 0.44 \times, p<0.05$ each $)$ in the adherent cells under simulated microgravity and in the spheroids. There was no significant alteration in the expression of MAPK1, MMP13, PTEN, and TP53. Conclusions: Simulated microgravity induces spheroid formation in human breast cancer cells within $24 \mathrm{~h}$ and alters gene expression toward modified adhesion properties, enhanced cell repair, and phenotype preservation. Further insights into the underlying mechanisms could open up the way toward new therapies.
\end{abstract}

Keywords: breast cancer, microgravity, multicellular spheroids, cultured neoplastic cells, gene expression

\section{Introduction}

Breast cancer is one of the most common malignancies worldwide, with a lifetime risk of $1-8$ for a woman in a western country (45). Although survival rate is improving, there is still the need to identify molecular mechanisms of breast cancer tumorigenesis to design targeted therapies. Concerning in vivo studies, it is well known that two-dimensional (2D) cell cultures struggle with various limitations. Particularly, the cytoskeleton has been shown to play a crucial role in epithelial to mesenchymal transition in tumor cells, being one of the steps on the way to invasion and spreading (25). The cytofilaments are virtually stretched and deformed in adherent, two-dimensionally aligned cells (40), making the simulation of in vivo conditions difficult. Matrix-free three-dimensional (3D) culture models such as liquid overlay (9) and matrix-bound models such as matrigel polymers or macroporous scaffolds are in use (42), all with various benefits and drawbacks. We chose simulated microgravity as a 3D culture model for several reasons: it is a scaffold-free model, eliminating any disturbance

\footnotetext{
Corresponding author: Armin Kraus, MD

Department of Plastic, Aesthetic and Hand Surgery, Otto-von-Guericke University

Leipziger Strasse 44, D-39120 Magdeburg, Germany

Phone: +49 39167 15599; Fax: +49 39167 15588; E-mail: armin.kraus@med.ovgu.de
} 
of cell function and morphology by the shape and material of the scaffold. Second, it could give some hints on tumor behavior during future space flights, as good correlation of cellular effects between simulated microgravity on earth and conditions during spaceflights has been reported $(13,24)$. Several studies have shown the importance of simulated microgravity experiments in tumor research. Several tumor cell lines have shown significant alterations in their properties, including proliferation, apoptosis, and migration (6). Thyroid cancer cells have been shown to be transformed into a less malignant phenotype. The authors conclude that identification of the responsible cellular mechanisms may be beneficial in the development of new therapies (18). Drug and therapy testing is another valuable application of simulated microgravity in tumor research. Sensitivity to cytostatic agents (36) as well as toward radiation (11) has been shown to increase under simulated microgravity. As a reaction to simulated microgravity, detachment from the culture surface and formation of 3D aggregates, so called spheroids, have been reported for thyroid cancer cells (41), chondrocytes (2), and tenocytes (17). In particular, for breast cancer cells, changes in cell migration and adhesion $(21,28)$, altered reaction to oxidative stress (47), and alteration in the cytoskeleton arrangement as well as in the expression of genes of the vascular endothelial growth factor pathway have been reported (16).

In this study, we aimed at evaluating the expression of genes related to invasion and adhesion as well as to tumor promotion and suppression. We particularly focused on medium-term effects after $24 \mathrm{~h}$ of simulated microgravity exposure.

\section{Materials and Methods}

\section{Cell culture}

Human breast cancer cells (adenocarcinoma, ATCC no. CRL-2351) as cultured neoplastic cells were obtained from ATCC ${ }^{\complement}$ (Wesel, Germany). The cell line is estrogen receptor negative and overexpresses the Her2/neu oncogene. Cells were first expanded under 2D conditions in T125 flasks (Sarstedt, Newton, USA) until cell number was sufficient for the experiments. Ham's F12-media (Gibco, Germany) was used supplemented with 5\% fetal calf serum (Biochrom AG, Berlin, Germany). An amount of 1\% penicillin/streptomycin (Biochrom, Germany) was added to prevent infection. Medium was changed three times a week. For the experiments, $1 \times 10^{6}$ cells were counted by hemocytometer and added to $n=6 \mathrm{~T} 125$ flasks for the experimental group in the random positioning machine (RPM) and to the same number of flasks for the control group under $1 g$ conditions.

\section{Random positioning machine (RPM)}

The RPM (developed by University of Applied Sciences, Northwestern Switzerland) was run with a commercially available incubator at $37^{\circ} \mathrm{C}$ and $5 \% \mathrm{CO}_{2}$. Angular velocity was $60^{\circ} / \mathrm{sin}$ a random walk manner. The method was intensively investigated and published earlier (43). Six T125 cm flasks were attached to the operating platform as much in the center as possible, and samples were rotated for $24 \mathrm{~h}$. Static, non-rotated controls were exposed to the same environmental conditions nearby the device.

\section{Phase contrast microscopy}

Phase contrast microscopy was performed for visual observation of the viability and morphology of the cells and for the detection of potential spheroids. A Leica microscope (Leica Microsystems GmbH, Wetzlar, Germany) was used. Phtographs were taken with a Canon EOS 60D (Canon GmbH, Krefeld, Germany). For taking the photographs, flasks were 
taken out of the RPM and put under the microscope as quickly as possible. Images were focused on a level showing spheroids and adherent cells simultaneously to allow comparison.

\section{Cell harvesting}

In the control group and for the adherent cells in the experimental group, cells were detached from the culture plate surface by incubation with $0.025 \%$ trypsine (Sigma-Aldrich, Germany) in combination with mechanical detachment with a cell scraper (Sigma-Aldrich), in the same way as for cell passaging. Cell harvest of the spheroids was performed as described earlier by our group (16). Supernatant from the T125 flasks was collected by pipetting off the supernatant and subsequent centrifugation at $300 \times g$ for $5 \mathrm{~min}$ in RNase-free tubes to collect the cell pellet.

\section{RNA isolation}

After collection of the cell pellets as described above, RNA isolation and quantitative realtime polymerase chain reaction (qPCR) were performed according to routine protocols as indicated in the manufacturer's manual. RNA was isolated using the RNeasy ${ }^{\odot}$ Kit (Qiagen, Hilden, Germany) following the manual's instructions. The pellet was lysed by adding $350 \mu \mathrm{l}$ of the lysis buffer (RLT, Qiagen). Cell-inherent RNases were inactivated by adding $1 \%$ $\beta$-mercaptoethanol. The lysate was homogenized by vortexing for $1 \mathrm{~min}$. It was then stabilized by adding 1 volume of $70 \%$ ethanol. After repeated centrifugation following the washing steps indicated in the manual, the RNA was eluted with $30 \mu \mathrm{l}$ of RNase-free water. The RNA was quantified by means of photometry via the SpectraMax M2 device (Molecular Devices, CA, USA).

\section{Reverse transcription}

RNA concentration was determined by measuring the absorbance at $260 \mathrm{~nm}$. Reverse transcription was performed using the First Strand cDNA Synthesis Kit (Thermo Scientific, Waltham, MA, USA) following the manufacturer's instructions; for each sample, an amount of $3 \mu \mathrm{g}$ random hexamer primers and nuclease-free water were added to the total volume of $11 \mu \mathrm{l}$. To this mixture, reaction buffer, RNase inhibitor, oligonucleotides, and reverse transcriptase were added to the total volume of $20 \mu \mathrm{l}$. All steps were carried out on ice. The solution was incubated for $5 \mathrm{~min}$ at $25^{\circ} \mathrm{C}$, followed by $37^{\circ} \mathrm{C}$ for $60 \mathrm{~min}$. The reaction was terminated by incubation at $70{ }^{\circ} \mathrm{C}$ for $5 \mathrm{~min}$. The cDNA solution was stored at $-20^{\circ} \mathrm{C}$ for less than 1 week before proceeding with the experiments.

\section{Quantitative real-time polymerase chain reaction ( $q P C R$ )}

The qPCR was utilized to determine the expression levels of target genes, shown in Table I, using the SYBR ${ }^{\circledR}$ Green PCR Master Mix (Applied Biosystems, Darmstadt, Germany) and the 7500 Fast Real-Time PCR System (Applied Biosystems). An amount of $10 \mu 1$ master mix, $1 \mu \mathrm{l}$ of forward and reverse primers each at a concentration of $400 \mathrm{nM}$ and $1-8 \mu 1$ of cDNA and RNase-free water, dependent on the input amount of RNA, were added. The following cycling steps were performed after activation of uracil-DNA Glycolase $\left(50^{\circ} \mathrm{C}\right.$ for $\left.2 \mathrm{~min}\right)$ and DNA polymerase $\left(95^{\circ} \mathrm{C}\right.$ for $2 \mathrm{~min}$ ): $95^{\circ} \mathrm{C}$ for $15 \mathrm{~s}$, and $60{ }^{\circ} \mathrm{C}$ for $1 \mathrm{~min}$ ( $40 \mathrm{cycles}$ ). Specific amplification was confirmed by dissociation curves. cDNA-selective primers were identified from the Harvard primer database (https://pga.mgh.harvard.edu/primerbank) and were synthesized by TIB Molbiol (Berlin, Germany). All samples were measured in triplicate and normalized to the housekeeping gene $18 \mathrm{~S}$ rRNA. Comparative $\mathrm{CT}(\Delta \Delta \mathrm{CT})$ methods 
Table I. Primers used for qPCR

\begin{tabular}{|c|c|}
\hline Primer sequence & Gene \\
\hline GCTCGTGGAAGATTTCGGTGT & \multirow[t]{2}{*}{$B R C A 1$} \\
\hline TCATCAATCACGGACGTATCATC & \\
\hline TGTGTCTCATATCAGGTTGACGA & \multirow[t]{2}{*}{$K R A S$} \\
\hline CAAGAGTCGAGTGTGGTCTCA & \\
\hline GGGAAGATGGTCGTGATCCTT & \multirow[t]{2}{*}{$V C A M 1$} \\
\hline TCTGGGGTGGTCTCGATTTTA & \\
\hline GACGCCATCAACACCGAGTT & \multirow[t]{2}{*}{$V I M$} \\
\hline CTTTGTCGTTGGTTAGCTGGT & \\
\hline TACACCAACCTCTCGTACATCG & \multirow[t]{2}{*}{$M A P K 1$} \\
\hline CATGTCTGAAGCGCAGTAAGATT & \\
\hline ACTGAGAGGCTCCGAGAAATG & \multirow[t]{2}{*}{$M M P 13$} \\
\hline GAACCCCGCATCTTGGCTT3' & \\
\hline TGGATTCGACTTAGACTTGACCT & \multirow[t]{2}{*}{ PTEN } \\
\hline GGTGGGTTATGGTCTTCAAAAGG & \\
\hline CAGCACATGACGGAGGTTGT & \multirow[t]{2}{*}{ TP53 } \\
\hline TCATCCAAATACTCCACACGC & \\
\hline ATGGCGGCGTCTGTATTAAAC & \multirow[t]{2}{*}{$18 S r R N A$} \\
\hline AGAACCATATCGCTCCTGGTAT & \\
\hline
\end{tabular}

All sequences are given in $5^{\prime}-3^{\prime}$ direction and were retrieved from the Harvard primer database (https://pga.mgh. harvard.edu/primerbank/). qPCR: quantitative real-time polymerase chain reaction

were used for relative quantification of transcription levels, with the control group set as $100 \%$. Primer sequences were as indicated in Table I.

Statistical analyses

All statistical analyses were performed using SPSS 21.0 (SPSS, Inc., Chicago, IL, USA, 2012). The data were analyzed using Mann-Whitney $U$ test. The data were expressed as means \pm standard deviation (SD). Differences were considered significant at $p<0.05$.

\section{Results}

\section{Light microscopy}

After $24 \mathrm{~h}$, incipient detachment of the cells from the culture surface was observed, with incipient formation of multicellular spheroids containing 10-15 cells. Although some cells detached from the culture surface, others still remained adherent, with no macroscopically recognizable difference in shape or morphology compared to the control cells under $1 g$ conditions (Fig. 1A). In the control group under $1 g$ conditions, cells showed typical shape of 
A

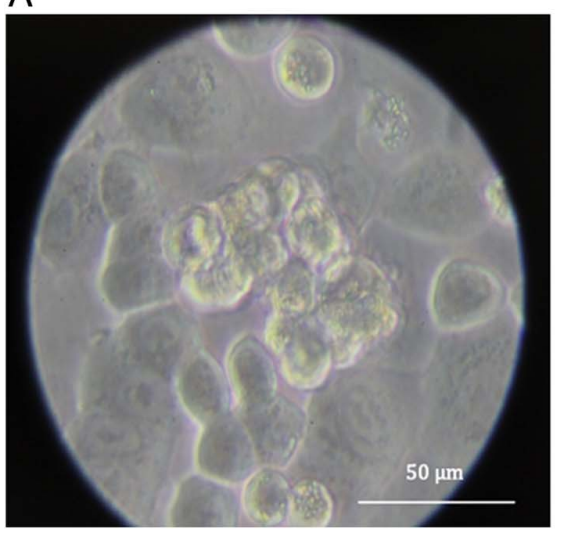

B

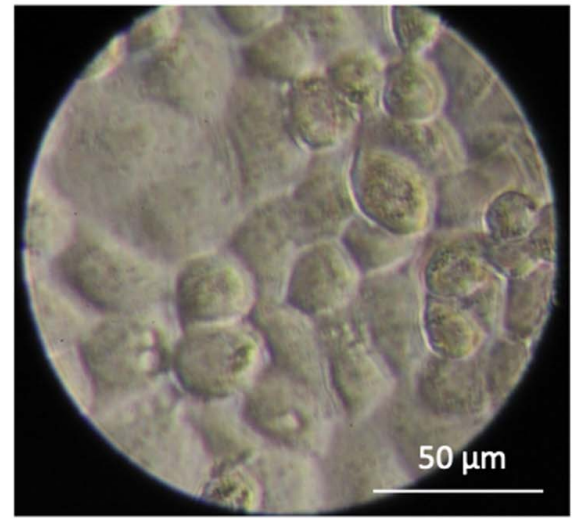

Fig. 1. Phase contrast microscopy. (A) Incipient detachment of the cells from the culture surface and formation of spheroids under simulated microgravity. (B) Breast cancer cells attached to the culture surface under $1 g$ conditions

cells attached to a culture surface with flat morphology with rectangular to hexagonal borders (Fig. 1B). All cells looked perfectly healthy, with lucent cytoplasm and round nuclei. Trypan blue staining revealed no difference in cell viability between cells under simulated microgravity and cells under $1 g$ conditions (data not shown).

\section{Real-time PCR}

BRCA1 expression was significantly increased $(1.9 \times, p<0.05)$ in the adherent cells under simulated microgravity compared to the $1 g$ control, but showed no alteration in the spheroids (Fig. 2A). Expression of KRAS was significantly decreased in the adherent cells $(0.6 \times$; $p<0.05)$ compared to the control. It was also slightly decreased in the spheroids, but the difference did not reach statistical significance (Fig. 2B). VCAM-1 was significantly upregulated (6.6× and $2.0 \times, p<0.05$ each) both in the adherent cells under simulated microgravity and in the spheroids compared to the control (Fig. 2C). VIM expression was significantly downregulated $(0.45 \times$ and $0.44 \times, p<0.05$ each) in the adherent cells under simulated microgravity and also in the spheroids compared to the control (Fig. 2D). There was no significant alteration in the expression of MAPK1, MMP13, PTEN, and TP53 for the adherent cells and for the spheroids compared to the $1 g$ control (Fig. 2E-I).

\section{Discussion}

In this study, we exposed human breast cancer cells to simulated microgravity in an RPM for $24 \mathrm{~h}$ and observed various alterations in both morphology and gene expression. Detachment of the cells from the culture surface and formation of spheroids could be found. This is in accordance with the results of Kopp et al. (16), who observed incipient cell detachment of another cell line of breast cancer cells under microgravity after $16 \mathrm{~h}$, with an increase in cluster size after $24 \mathrm{~h}$ and 5 days. The exact reasons for this phenomenon have not been fully elucidated to date, but Louis et al. previously suggested that some small GTPases of the Rho family that control several aspects of cell dynamics, such as vesicular transport and cytoskeleton turnover, might be the key in cell adaption to microgravity $(23,37)$. For cell 

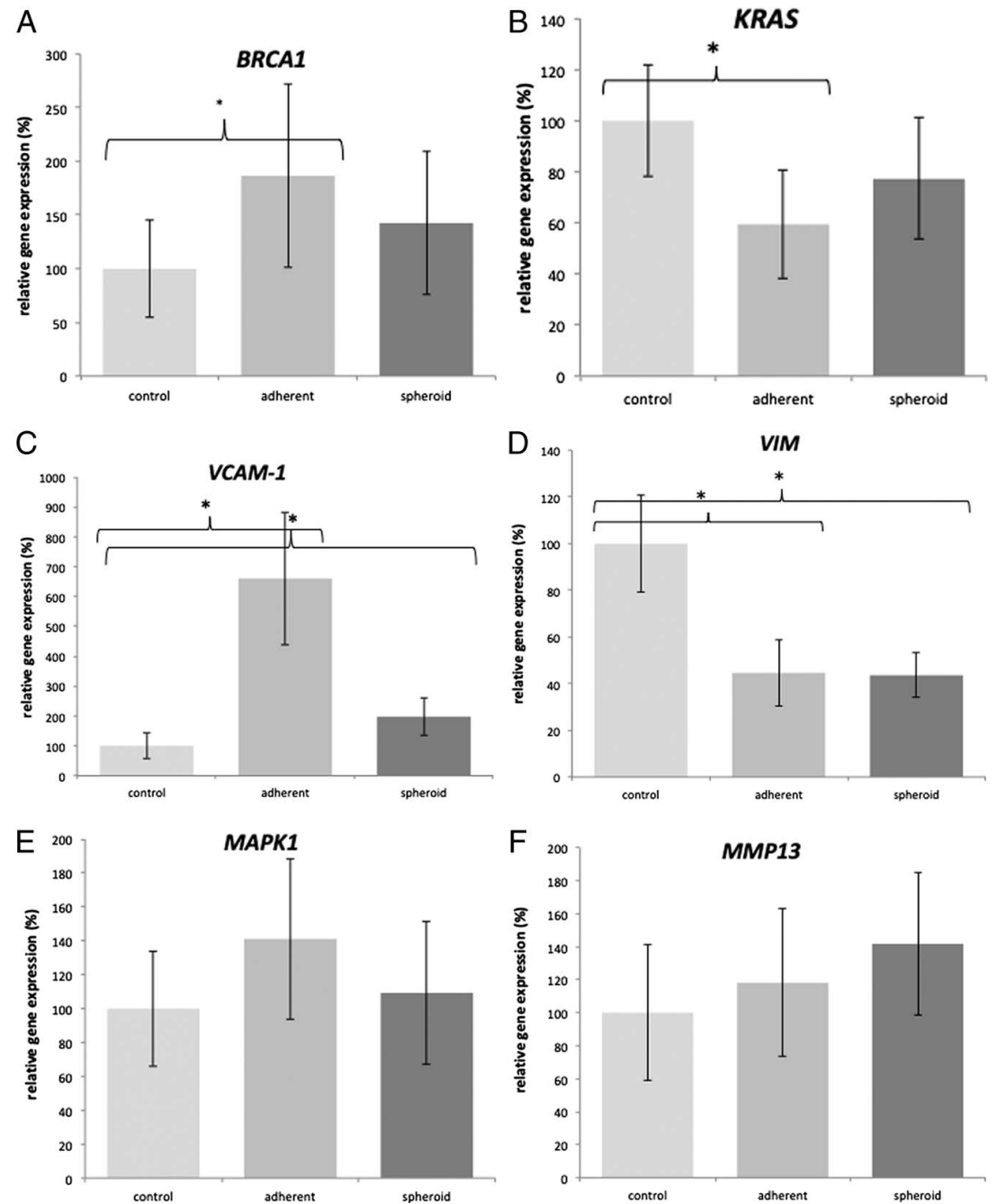

Fig. 2. Analysis of genes of interest by qPCR. (a) BRCA1 expression was significantly increased $(1.9 \times, p<0.05)$ in the adherent cells under microgravity compared to the $1 g$ control. (b) Expression of $K R A S$ was significantly decreased in the adherent cells $(0.6 \times, p<0.05)$ compared to the control. (c) VCAM1 was significantly upregulated $(6.6 \times, 2.0 \times, p<0.05$ each $)$ in the adherent cells under microgravity and in the spheroids compared to the control. (d) VIM expression was significantly downregulated $(0.45 \times, 0.44 \times, p<0.05$ each) in the adherent cells under microgravity and in the spheroids compared to the control also. (e) No significant alteration of $M A P K 1$ expression in the adherent cells under microgravity and in the spheroids compared to the $1 \mathrm{~g}$ control. (f) No significant alteration of MMP13 expression in the adherent cells under microgravity and in the spheroids compared to the $1 g$ control. (g) No significant alteration of PTEN expression in the adherent cells under microgravity and in the spheroids compared to the $1 g$ control. (h) No significant alteration of $p 53$ expression in the adherent cells under microgravity and in the spheroids compared to the $1 g$ control. $* p<0.05$ 


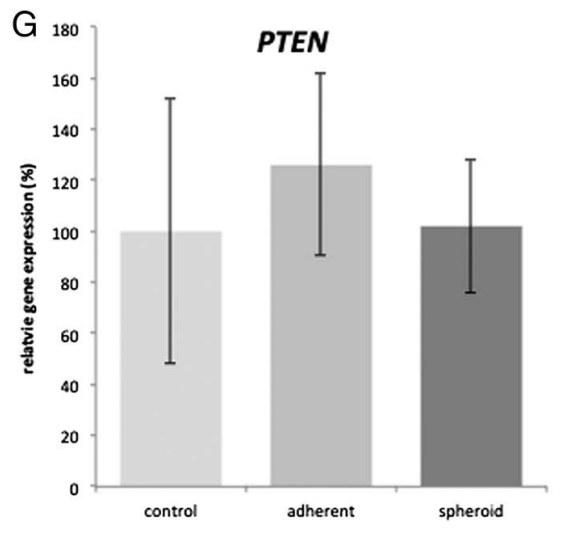

$\mathrm{H}$

Fig. 2. (continued)

detachment and readherence in spheroids under simulated microgravity, two different mechanisms can be conceived. Either, single cells detach from the surface and reassamble to spheroids in the fluid medium, or, as already described (10), cells may spread over each other on the culture plate to form little colonies, which detach as a whole after reaching a certain size. Further evaluation of this process might bring some insights into the mechanisms of metastasis formation. Concerning gene expression, we observed alterations for BRCA1, KRAS, VCAM1, and VIM. BRCA1 is known to act as an oncogene in the case of specific mutations (7). However, the normal function of its gene product lies in the preservation of chromosome structure and in the repair of double-strand breaks (39), thereby providing genomic stability. It is an ubiquitin 3 ligase that, interacting with the RAD51 protein for this purpose, plays a major role in the repair of DNA double-strand breaks (5). During spaceflight experiments, BRCA1 showed significant upregulation in embryonal stem cells, similarly to other DNA repair genes (4). We observed significant upregulation of BRCA1 in the adherent cells, which could indicate pronounced repair mechanisms under simulated microgravity. As it was reported previously, simulated microgravity acts as a weak genotoxin that induces DNA double-strand breaks particularly in cells with impaired DNA repair mechanisms (22). This effect is most pronounced after short-term exposure $(24 \mathrm{~h})$, so that some adaption effects are postulated. KRAS is a proto-oncogene encoding for a small GTPase. In its wild-type state, KRAS promotes cell cycle progression and acts as a tumor suppressor (14). Interestingly, it was reported that survival of lung cancer cells is dependent on KRAS activation in 3D culture and in vivo, but not in $2 \mathrm{D}$ culture $(26,46)$. We observed significant downregulation of KRAS in the adherent cells under simulated microgravity, but not in the spheroids. There may be several reasons for that, but a possible explanation is a transition of the cells toward a new equilibrium state with lower proliferation, but pronounced phenotype preservation and cell repair. VCAM-1 was more than sixfold upregulated in the adherent cells under simulated microgravity and twofold in the spheroids. It has been reported that VCAM-1 overexpression in breast cancer cells, by binding to its natural ligand $\alpha 4 \beta 1$ integrin, is responsible for metastasis formation in the lung, bone, and brain (34).

Vimentin is a major component of the intermediate filaments, providing resistance against mechanical stress in virtually all cell types (31). Vimentin is another cytoskeleton protein of importance in the migration and invasion of breast cancer cells (15). VIM expression was 
downregulated under simulated microgravity after $24 \mathrm{~h}$ in our experiments. Several experiments in space and under simulated microgravity with various cell types have shown tremendous changes in cytoskeleton shape and arrangement $(17,41)$. The cytoskeleton is known to be sensitive to external forces (29), showing alignment with the direction of force. Reduction of external forces to a minimum also seems to be a stimulus for the cytoskeleton, and there are theories that the cytoskeleton serves as a kind of "gravity sensor" (40), transmitting many of the effects of microgravity into inside the cell. With our panel of up- and downregulated genes, several pathway cross-talks could be conceived. For instance, transforming growth factor-beta (TGF- $\beta$ ) is known to bind to several transmembrane proteins (TMEMs), thereby inducing a variety of cascades which involve the genes altered under simulated microgravity in our experiments (32). Both the RAS-MEK-ERK cascade and the PI3K-AKT- $\beta$ catenein cascade, which control VCAM and MMP production eventually, are triggered by TGF- $\beta$ binding to TMEMs. The TMEM activation by simulated microgravity could therefore be postulated. Selective modification of this pathway induction by agents different from simulated microgravity could be useful for future therapeutics. Furthermore, the KRAS pathway is known to activate $M A P K 1$, whose expression was not found to be upregulated in our experiments. There are several possible explanations for that, but since we performed shorttime experiments and $M A P K 1$ lies downstream of $K R A S(30)$, delayed upregulation at a later time point can be conceived. In addition, $B R C A 1$ interacts with $p 53$, which is a downstream target of the KRAS cascade (38). It has been reported that p53 suppresses BRCA1 expression during cell stress conditions (3), so that upregulation of BRCA1 could be partially explained by decreased KRAS expression under simulated microgravity.

Taken together, our results discussed above may indicate some changes in invasive and metastatic behavior. We are aware that results from in vitro studies cannot be directly applied to in vivo conditions. However, invasion assays performed on melanoma cells in previous studies have shown significantly reduced invasiveness of cells grown under simulated microgravity, as well as reduced formation of metastatic colonies when implanted in an animal model later (37). Similar findings have been reported for glioblastoma cells (35). Future studies will have to show if these results also apply to different cell types, such as breast cancer cells. We also measured $M A P K 1$ expression, as it is a downstream target of the $K R A S$-activated pathway (27). Despite KRAS downregulation, we observed no change in $M A P K 1$ expression. To date, the exact reason for this is not fully clarified. The fact that MAPK1 lies downstream the KRAS pathway could account for some delay in $M A P K 1$ alteration, so measurements at a later time point could show different results. Matrix metalloproteinase 13 (MMP13) has been reported to enhance tumor growth and osteolytic capacity in breast cancer (33). We observed no significant changes in MMP13 expression in our experimental groups, although we expect an influence of the highly increased VCAM1 gene expression on CRL-2351 cell invasiveness, which should also be reflected in MMP13 expression. However, it is possible that MMP13 expression levels could show a delayed reaction to microgravity, with VCAM adhesion first taking place before invasion, so that changes could be observed at a later time point. We will evaluate this in future studies. The PTEN product has a protein tyrosine phosphatase domain that interacts with actin filaments at focal adhesions. Therefore, PTEN suppresses tumor cell growth by antagonizing protein tyrosine kinases and regulates tumor cell invasion and metastasis through interactions at focal adhesions $(20,44)$. We therefore considered PTEN gene expression worth measuring, but found no changes under simulated microgravity. As it is known, PTEN is antagonized by TGF- $\beta$ activity. We did not measure TGF- $\beta$ levels in our samples, but interestingly, higher TGF- $\beta$ production was reported for chondrocytes under simulated microgravity in an RPM (1). 
RAB27A is another small GTPase playing a role in breast cancer metastasis and will be investigated in more detail in our future studies (12). It controls the release of exosomes, which serve long-range communication for immune escape and metastatic niche preparation. P53 is a small G-protein that serves as a tumor suppressor gene. In case of DNA damage, p53 switches off cell replication and triggers apoptosis if repair fails (19). In our experimental groups, no increased expression of TP53 was detected; if anything, there was a tendency toward downregulation, albeit without significance. We therefore do not assume any apoptosis-promoting effect of $p 53$ in our experiments. For this study, we concentrated on morphology and alterations in gene expression. The results from Western blot confirmation in experiments with simulated microgravity require cautious interpretation, as microgravity is known to generally decrease protein synthesis in cells (8). We therefore decided to measure only gene expression changes in this study.

Taken together, we observed formation of spheroids in CRL-2351 breast cancer cells after $24 \mathrm{~h}$ in simulated microgravity, as it has been reported for various other cells lines cited above. Furthermore, we observed upregulation of BRCA1 and VCAM1, whereas KRAS and VIM were downregulated under simulated microgravity. These alterations are indicative of changes toward enhanced cell repair, modified adhesion properties, and phenotype preservation.

\section{Conclusions}

Simulated microgravity induces spheroid formation in human breast cancer cells and alters gene expression toward modified adhesion properties, enhanced cell repair, and phenotype preservation after $24 \mathrm{~h}$. Further insights into the underlying mechanisms could be helpful in the development of new therapies.

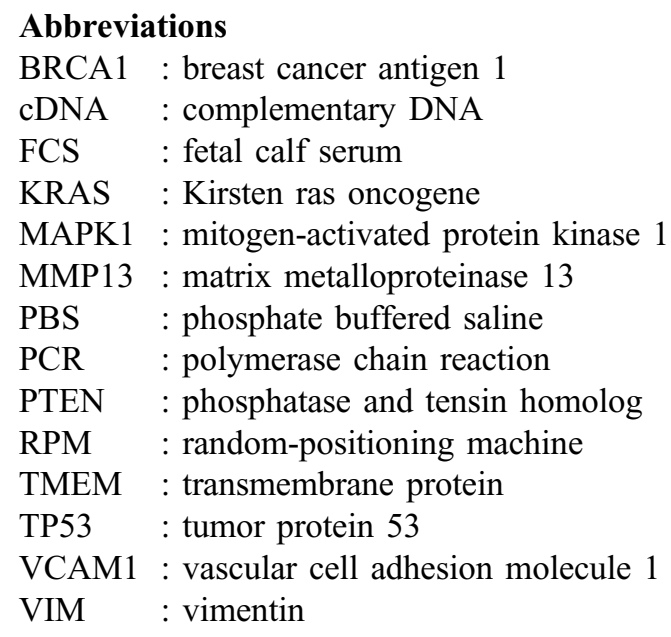

\section{Acknowledgements}

The authors would like to thank Markus Wehland, PhD for providing technical support with qPCR.

\section{Conflict of interest}

The authors declare no conflict of interest. 


\section{REFERENCES}

1. Aleshcheva G, Sahana J, Ma X, Hauslage J, Hemmersbach R, Egli M, Infanger M, Bauer J, Grimm D: Changes in morphology, gene expression and protein content in chondrocytes cultured on a random positioning machine. PLoS One 8, e79057 (2013)

2. Aleshcheva G, Wehland M, Sahana J, Bauer J, Corydon TJ, Hemmersbach R, Frett T, Egli M, Infanger M, Grosse J, Grimm D: Moderate alterations of the cytoskeleton in human chondrocytes after short-term microgravity produced by parabolic flight maneuvers could be prevented by up-regulation of BMP-2 and SOX-9. FASEB J. 29, 2303-2314 (2015)

3. Arizti P, Fang L, Park I, Yin Y, Solomon E, Ouchi T, Aaronson SA, Lee SW: Tumor suppressor p53 is required to modulate BRCA1 expression. Mol. Cell. Biol. 20, 7450-7459 (2000)

4. Blaber EA, Finkelstein H, Dvorochkin N, Sato KY, Yousuf R, Burns BP, Globus RK, Almeida EA: Microgravity reduces the differentiation and regenerative potential of embryonic stem cells. Stem Cells Dev. 24, 2605-2621 (2015)

5. Boulton SJ: Cellular functions of the BRCA tumour-suppressor proteins. Biochem. Soc. Trans. 34, 633-645 (2006)

6. Chen ZY, Guo S, Li BB, Jiang N, Li A, Yan HF, Yang HM, Zhou JL, Li CL, Cui Y: Effect of weightlessness on the 3D structure formation and physiologic function of human cancer cells. Biomed. Res. Int. 2019, 4894083 (2019)

7. Easton D, Ford D, Peto J: Inherited susceptibility to breast cancer. Cancer Surv. 18, 95-113 (1993)

8. Feger BJ, Thompson JW, Dubois LG, Kommaddi RP, Foster MW, Mishra R, Shenoy SK, Shibata Y, Kidane YH, Moseley MA, Carnell LS, Bowles DE: Microgravity induces proteomics changes involved in endoplasmic reticulum stress and mitochondrial protection. Sci. Rep. 6, 34091 (2016)

9. Froehlich K, Haeger JD, Heger J, Pastuschek J, Photini SM, Yan Y, Lupp A, Pfarrer C, Mrowka R, Schleussner E, Markert UR, Schmidt A: Generation of multicellular breast cancer tumor spheroids: comparison of different protocols. J. Mammary Gland Biol. Neoplasia. 21, 89-98 (2016)

10. Grimm D, Infanger M, Westphal K, Ulbrich C, Pietsch J, Kossmehl P, Vadrucci S, Baatout S, Flick B, Paul M, Bauer J: A delayed type of three-dimensional growth of human endothelial cells under simulated weightlessness. Tissue Eng. Part A 15, 2267-2275 (2009)

11. Hada M, Ikeda H, Rhone JR, Beitman AJ, Plante I, Souda H, Yoshida Y, Held KD, Fujiwara K, Saganti PB, Takahashi A: Increased chromosome aberrations in cells exposed simultaneously to simulated microgravity and radiation. Int. J. Mol. Sci. 20, 43 (2018)

12. Hendrix A, Hume AN: Exosome signaling in mammary gland development and cancer. Int. J. Dev. Biol. 55, 879-887 (2011)

13. Huang B, Liu N, Rong X, Ruan J, Huang Y: Effects of simulated microgravity and spaceflight on morphological differentiation and secondary metabolism of Streptomyces coelicolor A3(2). Appl. Microbiol. Biotechnol. 99, 4409-4422 (2015)

14. Jancik S, Drabek J, Radzioch D, Hajduch M: Clinical relevance of KRAS in human cancers. J. Biomed. Biotechnol. 2010, 150960 (2010)

15. Kokkinos MI, Wafai R, Wong MK, Newgreen DF, Thompson EW, Waltham M: Vimentin and epithelialmesenchymal transition in human breast cancer - observations in vitro and in vivo. Cells Tissues Organs. 185, 191-203 (2007)

16. Kopp S, Slumstrup L, Corydon TJ, Sahana J, Aleshcheva G, Islam T, Magnusson NE, Wehland M, Bauer J, Infanger M, Grimm D: Identifications of novel mechanisms in breast cancer cells involving duct-like multicellular spheroid formation after exposure to the random positioning machine. Sci. Rep. 6, 26887 (2016)

17. Kraus A, Luetzenberg R, Abuagela N, Hollenberg S, Infanger M: Spheroid formation and modulation of tenocytespecific gene expression under simulated microgravity. Muscles Ligaments Tendons J. 7, 411-417 (2018)

18. Kruger M, Melnik D, Kopp S, Buken C, Sahana J, Bauer J, Wehland M, Hemmersbach R, Corydon TJ, Infanger M, Grimm D: Fighting thyroid cancer with microgravity research. Int. J. Mol. Sci. 20, 2553 (2019)

19. Lane DP: Cancer. p53, guardian of the genome. Nature 358, 15-16 (1992)

20. Li J, Yen C, Liaw D, Podsypanina K, Bose S, Wang SI, Puc J, Miliaresis C, Rodgers L, McCombie R, Bigner SH, Giovanella BC, Ittmann M, Tycko B, Hibshoosh H, Wigler MH, Parsons R: PTEN, a putative protein tyrosine phosphatase gene mutated in human brain, breast, and prostate cancer. Science 275, 1943-1947 (1997)

21. Li J, Zhang S, Chen J, Du T, Wang Y, Wang Z: Modeled microgravity causes changes in the cytoskeleton and focal adhesions, and decreases in migration in malignant human MCF-7 cells. Protoplasma 238, 23-33 (2009) 
22. Li N, An L, Hang H: Increased sensitivity of DNA damage response-deficient cells to stimulated microgravityinduced DNA lesions. PLoS One 10, e0125236 (2015)

23. Louis F, Deroanne C, Nusgens B, Vico L, Guignandon A: RhoGTPases as key players in mammalian cell adaptation to microgravity. Biomed. Res. Int. 2015, 747693 (2015)

24. Martinez EM, Yoshida MC, Candelario TL, Hughes-Fulford M: Spaceflight and simulated microgravity cause a significant reduction of key gene expression in early T-cell activation. Am. J. Physiol. Regul. Integr. Comp. Physiol. 308, R480-R488 (2015)

25. McCaffrey LM, Macara IG: Epithelial organization, cell polarity and tumorigenesis. Trends Cell Biol. 21, 727-735 (2011)

26. McCormick F: KRAS as a therapeutic target. Clin. Cancer Res. 21, 1797-1801 (2015)

27. Nan X, Tamguney TM, Collisson EA, Lin LJ, Pitt C, Galeas J, Lewis S, Gray JW, McCormick F, Chu S: Ras-GTP dimers activate the mitogen-activated protein kinase (MAPK) pathway. Proc. Natl. Acad. Sci. U. S. A. 112, 7996-8001 (2015)

28. Qian A, Zhang W, Li X, Weng Y, Tian Z, Di S, Yang P, Yin D, Hu L, Xu Z, Shang P: Simulated weightlessness alters biological characteristics of human breast cancer cell line MCF. Acta Astronaut. 63, 947-958 (2008)

29. Riboh J, Chong AK, Pham H, Longaker M, Jacobs C, Chang J: Optimization of flexor tendon tissue engineering with a cyclic strain bioreactor. J. Hand Surg. Am. 33, 1388-1396 (2008)

30. Sanchez-Vega F, Mina M, Armenia J, Chatila WK, Luna A, La KC, Dimitriadoy S, Liu DL, Kantheti HS, Saghafinia S, Chakravarty D, Daian F, Gao Q, Bailey MH, Liang WW, Foltz SM, Shmulevich I, Ding L, Heins Z, Ochoa A, Gross B, Gao J, Zhang H, Kundra R, Kandoth C, Bahceci I, Dervishi L, Dogrusoz U, Zhou W, Shen H, Laird PW, Way GP, Greene CS, Liang H, Xiao Y, Wang C, Iavarone A, Berger AH, Bivona TG, Lazar AJ, Hammer GD, Giordano T, Kwong LN, McArthur G, Huang C, Tward AD, Frederick MJ, McCormick F, Meyerson M, Cancer Genome Atlas Research N, Van Allen EM, Cherniack AD, Ciriello G, Sander C, Schultz N: Oncogenic signaling pathways in the cancer genome atlas. Cell 173, 321-37.e10 (2018)

31. Satelli A, Li S: Vimentin in cancer and its potential as a molecular target for cancer therapy. Cell. Mol. Life Sci. 68, 3033-3046 (2011)

32. Schmit K, Michiels C: TMEM proteins in cancer: a review. Front. Pharmacol. 9, 1345 (2018)

33. Shah M, Huang D, Blick T, Connor A, Reiter LA, Hardink JR, Lynch CC, Waltham M, Thompson EW: An MMP13-selective inhibitor delays primary tumor growth and the onset of tumor-associated osteolytic lesions in experimental models of breast cancer. PLoS One 7, e29615 (2012)

34. Sharma R, Sharma R, Khaket TP, Dutta C, Chakraborty B, Mukherjee TK: Breast cancer metastasis: putative therapeutic role of vascular cell adhesion molecule-1. Cell. Oncol. (Dordr.). 40, 199-208 (2017)

35. Shi ZX, Rao W, Wang H, Wang ND, Si JW, Zhao J, Li JC, Wang ZR: Modeled microgravity suppressed invasion and migration of human glioblastoma U87 cells through downregulating store-operated calcium entry. Biochem. Biophys. Res. Commun. 457, 378-384 (2015)

36. Takeda M, Magaki T, Okazaki T, Kawahara Y, Manabe T, Yuge L, Kurisu K: Effects of simulated microgravity on proliferation and chemosensitivity in malignant glioma cells. Neurosci. Lett. 463, 54-59 (2009)

37. Tan X, Xu A, Zhao T, Zhao Q, Zhang J, Fan C, Deng Y, Freywald A, Genth H, Xiang J: Simulated microgravity inhibits cell focal adhesions leading to reduced melanoma cell proliferation and metastasis via FAK/ RhoA-regulated mTORC1 and AMPK pathways. Sci. Rep. 8, 3769 (2018)

38. Taneja P, Maglic D, Kai F, Zhu S, Kendig RD, Fry EA, Inoue K: Classical and novel prognostic markers for breast cancer and their clinical significance. Clin. Med. Insights Oncol. 4, 15-34 (2010)

39. Venkitaraman AR: Cancer susceptibility and the functions of BRCA1 and BRCA2. Cell 108, 171-182 (2002)

40. Vorselen D, Roos WH, MacKintosh FC, Wuite GJ, van Loon JJ: The role of the cytoskeleton in sensing changes in gravity by nonspecialized cells. FASEB J. 28, 536-547 (2014)

41. Warnke E, Pietsch J, Wehland M, Bauer J, Infanger M, Gorog M, Hemmersbach R, Braun M, Ma X, Sahana J, Grimm D: Spheroid formation of human thyroid cancer cells under simulated microgravity: a possible role of CTGF and CAV1. Cell Commun. Signal. 12, 32 (2014)

42. Weigelt B, Ghajar CM, Bissell MJ: The need for complex 3D culture models to unravel novel pathways and identify accurate biomarkers in breast cancer. Adv. Drug Deliv. Rev. 69-70, 42-51 (2014)

43. Wuest SL, Richard S, Kopp S, Grimm D, Egli M: Simulated microgravity: critical review on the use of random positioning machines for mammalian cell culture. Biomed. Res. Int. 2015, 971474 (2015)

44. Yin Y, Shen WH: PTEN: a new guardian of the genome. Oncogene 27, 5443-5453 (2008) 
45. Yu XQ, De Angelis R, Luo Q, Kahn C, Houssami N, O’Connell DL: A population-based study of breast cancer prevalence in Australia: predicting the future health care needs of women living with breast cancer. BMC Cancer 14, 936 (2014)

46. Zhang Z, Jiang G, Yang F, Wang J: Knockdown of mutant K-ras expression by adenovirus-mediated siRNA inhibits the in vitro and in vivo growth of lung cancer cells. Cancer Biol. Ther. 5, 1481-1486 (2006)

47. Zheng H, Tian W, Yan H, Jiang H, Liu S, Yue L, Han F, Wei L, Chen X, Li Y: Expression of estrogen receptor $\alpha$ in human breast cancer cells regulates mitochondrial oxidative stress under simulated microgravity. Adv. Space Res. 49, 1432-1440 (2012) 